patients who had a return of the neutrophil count to normal after splenectomy. Two patients died within two months of operation; both probably had septicemia. Two patients continued to be neutropenic and to have recurrent infections. Like Barnes and his co-workers these authors recommend splenectomy for patients with Felty's syndrome and recurrent infections, but they state that one possible contraindication may be a lymphocytosis of the bone marrow, as that may indicate another disorder as the cause of the neutropenia.

In other series $6-8$ reported from the United States increase in granulocyte counts persisted in 12 of 14 patients followed up over one year. Established preoperative infection was the main threat and was associated with most of the high early mortality -6 out of 24 patients. The initial haematological response to splenectomy was as good in the London Hospital series as had previously been described by others ${ }^{7} \quad{ }^{10}$ and was associated with comparable clinical improvement, but only three of the London Hospital patients have now completely normal blood counts $14 \frac{1}{2}, 8 \frac{1}{2}$, and 6 years respectively after operation. Though splenectomy is frequently life-saving and an essential operation in many cases of Felty's syndrome, prolonged follow-up studies do not appear to show as good results as the early postoperative clinical and haematological picture would have suggested. Unfortunately corticosteroids only rarely produce lasting remission and may render the patient more vulnerable to cross-infection. Felty's syndrome remains an unexplained challenge to both rheumatologist and haematologist.

1 Felty, A. R., Bulletin of the fohns Hopkins Hospital, 1924, 35, 16.

2 Faber, V., Elling, P., Norup, G., Mansa, B., and Nissen, N. I., Lancet, $1964,2,344$.

Barnes, C. G., Turnbull, A. L., and Vernon-Roberts, B., Annals of the Rheumatic Diseases, 1971, 30, 359.

- Cudkowicz, L., Rheumatism, 1956, 12, 37.

5 Moor, R. A., Brunner, C. M., Sandusky, W. R., and Leavell, B. S., Annals of Internal Medicine, 1971, 75, 381.

O'Neill, J. A., jun., Scott, H. W., Billings, F. T., and Foster, J. H., Annals of Surgery, 1968, 167, 81.

' Ruderman, M., Miller, L. M., and Pinals, R. S., Arthritis and Rheumatism, $1968,11,377$.

Sandusky, W. R., Rudolf, L. E., and Leavell, B. S., Annals of Surgery, 1968, 167, 744 .

- de Gruchy, G. C., Geriatrics, 1965, 20, 219.

10 Collier, R. L., and Brush, B. E., American fournal of Surgery, 1966, 112, 869.

\section{Hazards of Colostomy Closure}

Closure of a colostomy might be regarded as a relatively minor procedure, particularly in comparison with the colonic resection for cancer or diverticular disease that often precedes it. Yet every surgeon knows that the morbidity of this operation is high and that even death can follow.

In a detailed study of this problem A. J. S. Knox, F. D. H. Burkett, and C. D. Collins ${ }^{1}$ have recently reviewed 179 patients in whom closure of colostomy was performed. Sixty $(33 \%)$ developed local complications. Of these, breakdown of colostomy requiring further operation occurred in 13 cases $(7 \%$ of the 179$)$, and a further $29(16 \%)$ developed a faecal fistula which closed spontaneously. Another 18 patients $(10 \%)$ developed wound infection without frank faecal discharge. There were four deaths (2.2\%) attributable to the operation, three of them associated with generalized peritonitis. Fewer complications followed extraperitoneal closure of the colostomy than the intraperitoneal procedure, though the difference was not statistically significant. How- ever, the deaths all followed intraperitoneal closure, so that the extraperitoneal technique does appear to be safer.

An interesting finding from this study was that the time interval between definitive surgery and closure of the colostomy had a distinct effect on the incidence of complications. The optimum time for closure of the colostomy was three months after the operation for diverticular disease, whereas a period of one or two months was sufficient in patients who had had a carcinoma resected.

An unusual complication of colostomy closure is postoperative tension pneumoderitoneum. An example of this was recorded by E. S. R. Hughes and colleagues. ${ }^{2}$ Progressive abdominal distension began seven days after colostomy closure. Paracentesis of the gas-filled Deritoneal cavity was performed four days later, with considerable imorovement, but the patient became uraemic and died a week later without reaccumulation of gas in the peritoneal cavity. These authors also record two further cases of tension pneumoperitoneum after partial colectomy. One patient, subjected to early laparotomy and drainage, survived; the other, for whom surgery was delayed, died. As a result of this experience, prompt laparotomy and drainage were advised. R. Hall ${ }^{3}$ now reports on three patients who developed tension pneumoperitoneum after intraperitoneal closure of their colostomies, the syndrome occurring respectively on the fifth, the seventh, and the thirteenth postoperative day. In each case peristalsis had been re-established and at least flatus had passed. The author suggests that the leakage of gas into the peritoneum occurs through a weak point in the suture line during a period of incoordinated colonic mass contraction associated with inadequate anal relaxation. In all three patients gross gaseous distension of the abdomen took place, and in two there was severe respiratory embarrassment. All three cases were treated conservatively, the twowith respiratory embarrassment by paracentesis either with a trocar or via the wound drain. In the third case relief was obtained by passing a flatus tube into the distended bowel through a sigmoidoscope. Two of the patients made an uneventful recovery on this conservative regimen, while the third developed a subphrenic abscess, which was drained, but thereafter progress was satisfactory.

Tension pneumoperitoneum is worth bearing in mind as an unusual complication of colostomy closure, resection of the colon, and even appendicectomy. ${ }^{4}$ If respiratory embarrassment is severe, simple deflation may be life-saving and should be instituted at once. Further close observation will then indicate whether the symptoms and signs completely resolve, in which case laparotomy can be avoided, or whether escape of faecal fluid, peritonitis, or later formation of a local abscess indicates operative intervention.

\footnotetext{
1 Knox, A. J. S., Birkett, F. D. H., and Collins, C. D., British fournal of Surgery, $1971,58,669$.
Hughes,

Hughes, E. S. R., Cuthbertson, A. M., and Buntine, J. A., British fournal of Surgery, 1964, 51, 274

3 Hall, R., British fournal of Surgery, 1971, 58, 574

- Millar, D. M., British fournal of Surgery, 1962, 49, 394.
}

\section{Ganglion Cysts of Bones}

The term ganglion was first used by Hippocrates to designate a knot of tissue filled with "mucoid flesh." It is a cystic swelling, $1-3 \mathrm{~cm}$ in diameter, found typically in close proximity to joints and tendon sheaths, the commonest sites being the dorsal and volar aspects of the wrist, the dorsum of 
the foot, and round the ankle and the knee. Though ganglia occur at all ages, their maximum incidence is in young, slightly-built women. ${ }^{1}$ They are well demarcated and movable within the surrounding tissue, and while often loosely attached to a tendon sheath or the capsule of a joint they do not communicate with the cavity. The dense fibrous capsule encloses cysts containing a viscid, jelly-like fluid rich in hyaluronic acid and other acid mucopolysaccharides. ${ }^{2}$ Histologically there are lakes of mucoid material surrounded and intersected by collagen fibres.

The pathogenesis of this common lesion is still debated. The most popular view ascribes it to myxomatous degeneration of connective tissue with the formation of cysts. ${ }^{12}$ Some workers have suggested that there is first a proliferation of fibroblasts secreting muconolysaccharide, and that the degeneration and cystic change are secondary. ${ }^{3}{ }^{4}$ An alternative view, that the ganglion originates from an out-pouching of synovial membrane through a defect in a joint capsule or a tendon sheath, can seldom be substantiated by dissection, but it is possible that the original connexion underwent attenuation during the evolution of the lesion. The aetiology of the ganglion is unknown. Occasionally there is a history of recent trauma, and excessive strain on a constitutionally weak connective tissue is possibly a factor. ${ }^{2}$

The occurrence of ganglion cysts in bone was first noted by J. D. Hicks in $1956,{ }^{5}$ and since then there have been a number of other reports. ${ }^{4-9}$ These intraosseous ganglion cysts are solitary and are usually situated near the adjacent joint. The bones round the ankles, especially the tibia, are most commonly affected, but lesions of the ulna, carpal bones, femur, acetabulum, and tarsal bones have also been reported. The patient feels aching discomfort in the neighbouring joint during activity, and, while physical examination is usually negative, $x$-rays disclose a well-defined cystic lesion extending to the subchrondral bone. A striking zone of sclerotic bone usually surrounds the cyst. Grossly the cyst may be unilocular or less commonly multilocular, and histologically there is the dense fibrous wall and mucoid gelatinous contents typical of the soft-tissue ganglion. F. H. Sim and D. C. Dahlin ${ }^{10}$ have recently reported six further cases of intraosseous ganglion cyst, five arising in the bones round the ankle and one in the head of the fibula and causing pain in the lateral aspect of the knee. The patients' ages varied from 32 to 86 years, and four of the six were men. The fibular cyst caused cortical expansion of the bone, an unusual change in this type of lesion. 46 The cavities of the cysts were curetted and then packed with bone chips. In two cases there were later recurrences, but all were finally cured.

The pathogenesis of these cysts is as obscure as that of the soft-tissue ganglion. They are to be distinguished from other bone cysts, especially the juxta-articular cysts found in degenerative disease of the joints. The absence of the other stigmata of joint disease, the solitary nature and larger size of the cyst, and the zone of condensed bone round it are useful diagnostic features of the ganglion lesion. Simple, or single-chambered, bone cysts may also cause confusion, but their contents are serious or serosanguineous and there are giant cells in the wall. Cysts of this type are usually situated in the metaphysis of a bone rather than in the ends, and the patients are usually younger than those with intraosseous ganglion cysts. The ganglion cysts are noteworthy because they can produce symptoms suggesting primary joint disease. Once they are adequately treated the discomfort ceases.
1 Carp, L., and Stout, A. P., Surgery, Gynecology and Obstetrics, 1928, $47,460$.

Soren, A., Clinical Orthopaedics, 1966, 48, 173

King, E. S. J., Australian and New Zealand fournal of Surgery, 1932, 1, 367. Goldman, R. L., and Friedman, N. B., Clinical Orthopaedics, 1969, $63,184$.

5 Hicks, J. D., Australian and New Zealand fournal of Surgery, 1956, 26, 138. - Woods, C. G., fournal of Bone and foint Surgery (British), 1961, 43, 758. ? Crabbe, W. A., British fournal of Surgery, 1966, 53, 15.

- Crane, A. R., and Scarano, J. J., fournal of Bone and foint Surgery (American), 1967, 49, 355 .

- Seymour, N., fournal of Bone and foint Surgery (British), 1968, 50, 134.

$10 \mathrm{Sim}, \mathrm{F}$. H., and Dahlin, D. C., Mayo Clinic Proceedings, 1971, 46, 484.

\section{Screening for Spastics}

"A baby, before it is seven days old, should be given a screening test to try to discover whether it is or may become spastic." 1 This recommendation, widely publicized last week by the national press and radio, was based on a report published by the Spastics Society; ${ }^{2}$ but it must have surprised many paediatricians, obstetricians, and general practitioners.

About 2 per thousand liveborn children will subsequently prove to have cerebral palsy, so there are about 2,000 new cases per year in the United Kingdom. No organization has done more than the Spastics Society to finance research and-with unusual vision-medical education on this subject, and to provide practical services for spastic children and their families. The report therefore deserves to be taken seriously. The recommendation on neonatal screening should be seen in context as a short paragraph in a 10-page document. The main message of the report is that if existing knowledge were universally applied one-quarter of these patients need never be affected and the degree of handicap could be greatly reduced in many of the others.

In the prevention of cerebral palsy the importance of perinatal care is rightly emphasized. Fetal monitoring during labour, and facilities for immediate resuscitation of the asphyxiated newborn baby and for intensive care of the low-birthweight or sick newborn, can reduce not only neonatal mortality but also the later incidence of neurological handicap. ${ }^{3}$ The report is right, too, in pointing out that the provision of services for the care and education of children with cerebral palsy is patchy and often grossly inadequate. These children frequently have multiple handicaps, and to achieve their full potential they may require the help of physiotherapists, orthopaedic surgeons, ophthalmologists, speech therapists, psychologists, occupational therapists, and psychiatrists, together with special educational services, all of which must be co-ordinated by, say, a paediatrician. ${ }^{4}$ Services for handicapped children have not always competed successfully with more glamorous branches of medicine for available resources, and the tone of urgency and impatience in the Spastics Society's report is not only wholly justified but will be welcomed by doctors working in this field.

The report's demand for universal neurological screening examinations in newborn babies is much more controversial. Screening examinations are worthwhile only if, firstly, a reliable screening examination is available which will not give many false negative or positive results; if, secondly, early detection is valuable because early treatment has proved advantages; and if, finally, the use of medical and other resources for screening is a reasonable priority in terms of the total supply of these resources and the demands made on them. None of these requirements has so far 